\title{
Hyperventilation or exercise to induce asthma?
}

\author{
PM TWEEDDALE, DJ GODDEN, IWB GRANT
}

From the Respiratory Unit, Respiratory Medicine Service, Northern General Hospital, and the Pulmonary Function Laboratory, Department of Medicine, Western General Hospital, Edinburgh

ABSTRACT Bronchoconstriction was induced in asthmatic patients by means of isocapnic hyperventilation with dry air. Responses both within a day and between days did not differ significantly: and corresponded closely with those observed after exercise. The mean fall in forced expiratoryo volume in one second $\left(\mathrm{FEV}_{1}\right)$ observed with both techniques was equivalent to $36 \%$. Isocapnic을 hyperventilation with dry air, as used in this study, was a potent stimulus and provoked a reproduc- $\vec{\rightarrow}$ ible response. The method was physically less demanding than exercise and was more acceptable to patients.

As early as the seventeenth century, it was recognised that asthma could be provoked by exercise, and it was stated that "Those exercises that move the arms, exercise the lungs moste". ${ }^{1}$ Thus, Anderson et al ${ }^{2}$ found that jogging on a treadmill produced a greater fall in peak expiratory flow rate in asthmatics than exercise on a bicycle ergometer. However, others $^{3}$ found that provided rates of oxygen uptake were matched in the two forms of exercise, they were equipotent in effect. More recent research ${ }^{45}$ has shown that the triggering stimulus for exerciseinduced asthma (EIA) may be cooling of the airways. During inspiration, air is warmed and humidified by heat and water loss from the mucosa. This loss is caused by convection and evaporation and therefore the degree of mucosal cooling depends on the temperature and humidity of inspired air, and minute ventilation. Isocapnic hyperventilation has been proposed as a practical alternative to exercise for inducing bronchoconstriction. ${ }^{6}$ ? It has also been suggested that the effect of hyperventilation can be maximised by cooling the inspired air. ${ }^{8}$ We have studied isocapnic hyperventilation with dry air to determine magnitude and reproducibility of response in a group of asthmatic patients.

\section{Methods}

Ten patients were studied, six male and four female, aged between 13 and 37 years. Seven were atopic. All gave a clinical history suggestive of exerciseinduced asthma. None had previously performed

Address for reprint requests: Dr IWB Grant, Respiratory Unit, Respiratory Medicine Service, Northern General Hospital, Edinburgh. controlled laboratory tests. Informed consent was. given by the patients or parents of patient whereo appropriate. Each was requested to stop all medication for $\mathbf{2 4}$ hours before the laboratory visits.

Patients attended for tests on two separate $\frac{\mathbb{Q}}{\mathbb{Q}}$ afternoons within a two-week period. On day $1, \varrho$ two isocapnic hyperventilation tests with dry를 air were performed (tests A and B), separated by a 3 three-hour interval. On day 2 , another hyperventilation test (test $\mathrm{C}$ ) and an exercise test were performed, again three hours apart. The order of test $\mathrm{C}$ and exercise was allocated randomly.

Isocapnic hyperventilation was carried out using an $\times$ open circuit (figure) with the expiratory side based 3 on the method of Deal et al. ${ }^{7}$ Patients initially. breathed, at rest, to and from room air, and end-윽 tidal carbon dioxide concentration was recorded. The circuit was then adjusted so that the patient? breathed in dry air from the cylinder via the inspira- $\frac{D}{8}$ tory reservoir $(6 \mathrm{l})$ and out to the expiratory bag (6 1). The expiratory bag was connected to a vacuum $N_{\mathscr{O}}$ cleaner (Electrolux) fitted with a variable transformer and the vacuum was set at the target ventilation rate. The patient was instructed to breathe fast enough to maintain inflation of the expiratory bag. Inspired ventilation was recorded using a drye gas meter (Parkinson-Cowan) and ink recorder (Mingograf 81). Hyperventilation was maintained for six minutes. End-tidal carbon dioxide was measured by infrared analysis (Capnograph) and $\frac{\mathcal{D}}{\mathbb{D}}$ monitored throughout the hyperventilation period. $\frac{\odot}{\mathbb{Q}}$ Carbon dioxide vas added as necessary to theo inspired air to maintain end-tidal carbon dioxide at resting level (on average $0 \cdot 25-2 \mathrm{l} / \mathrm{min}$ ). The targeto hyperventilation rate was set for each individual ato 


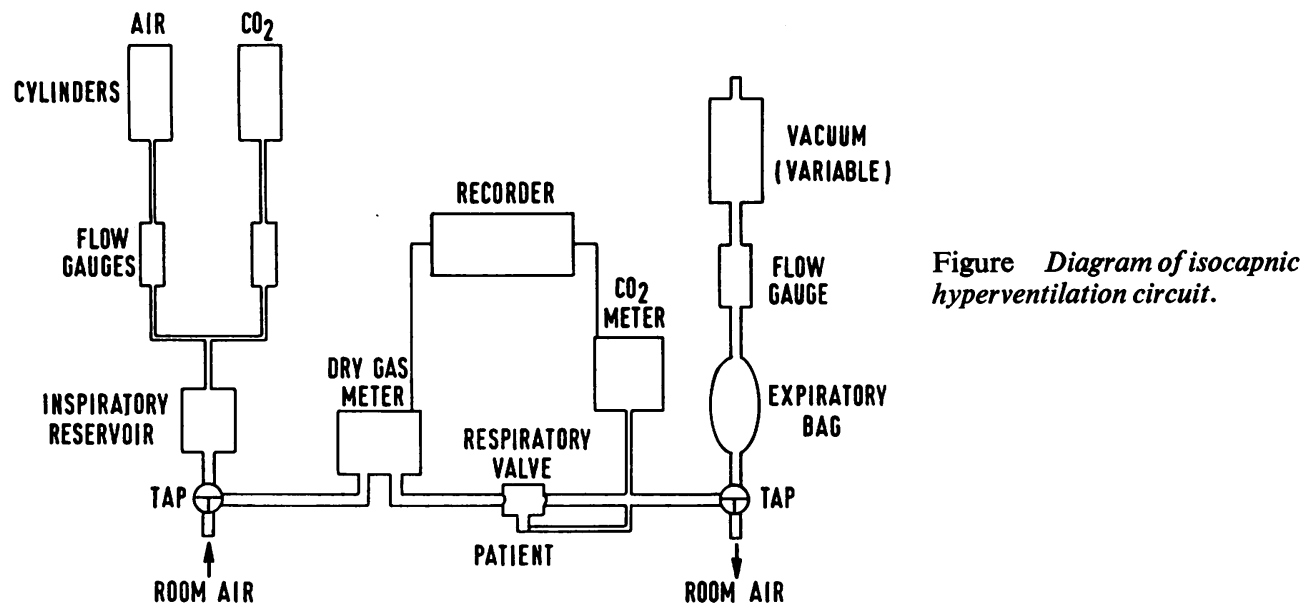

the four-minute maximum voluntary ventilation (predicted from $\mathrm{FEV}_{1}$ ) by the formula of Clark et al. ${ }^{\circ}$

The exercise test on day 2 took the form of six minutes jogging or walking on a treadmill (cardioexercise treadmill, Quinton Instruments). The slope was set at $10 \%$, and speed adjusted to achieve the desired minute ventilation. Cylinder air was breathed throughout the exercise.

FEV $_{1}$ and forced vital capacity (FVC) were measured at 1, 5, 10, and 15 minutes after each hyperventilation and exercise period. Statistical analysis was by paired $t$ test using both actual FEV 1 values and logarithms of the values.

\section{Results}

FEV 1 recordings before, and the lowest recorded value after each stimulus, are shown in the table, together with ventilation rates. Any difference in pre-test $\mathrm{FEV}_{1}$ within or between days was taken into account in calculating target ventilation rate. All patients showed a fall in $F_{1}$ after each stimulus with the exception of patient 5 on day 1 . Patients were allowed to recover spontaneously

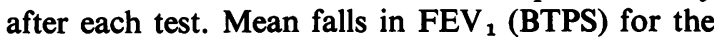
group in tests A and B were 1.001 (SD 0.26) and 1.09 (SD 0.34) respectively. Mean falls in test C and exercise were 0.96 1 (SD 0.28) and 1.16 l (SD $0 \cdot 27$ ) respectively. These figures represent a fall in FEV $_{1}$ of approximately $36 \%$.

Responses to hyperventilation were insignificantly different both within a day (tests A and B) and between days (where test $C$ was performed first on day 2 , comparison was made with test $\mathrm{A}$, and where second, with test B). This was true whether actual

Table Recordings of FEV $V_{1}(i)$ before and (ii) after isocapnic hyperventilation (tests $A, B$, and $C$ ) and exercise

\begin{tabular}{|c|c|c|c|c|c|c|c|c|c|c|c|c|c|c|}
\hline \multirow{4}{*}{$\begin{array}{l}\text { Patient } \\
\text { number }\end{array}$} & \multirow{4}{*}{$\begin{array}{l}\text { Age } \\
(y r)\end{array}$} & \multirow[t]{4}{*}{ Atopy } & \multicolumn{6}{|c|}{ Day I } & \multicolumn{6}{|c|}{ Day 2} \\
\hline & & & \multirow{2}{*}{\multicolumn{2}{|c|}{$\frac{\text { Test } A}{F E V_{1}}$}} & \multirow[b]{3}{*}{$V_{\mathbf{E}}$} & \multirow{2}{*}{\multicolumn{2}{|c|}{$\frac{\text { Test } B}{F E V_{1}}$}} & \multirow[b]{3}{*}{$V_{E}$} & \multirow{2}{*}{\multicolumn{2}{|c|}{$\frac{\text { Test } C}{F E V_{1}}$}} & \multirow[b]{3}{*}{$V_{\mathrm{E}}$} & \multirow{2}{*}{\multicolumn{2}{|c|}{$\frac{\text { Exercise }}{F E V_{1}}$}} & \multirow[b]{3}{*}{$V_{E}$} \\
\hline & & & & & & & & & & & & & & \\
\hline & & & $i$ & $i i$ & & $i$ & $i i$ & & $i$ & $i i$ & & $i$ & $i i$ & \\
\hline $\begin{array}{l}1 \\
2 \\
3 \\
4 \\
5 \\
6 \\
7 \\
8 \\
9 \\
10\end{array}$ & $\begin{array}{l}21 \\
13 \\
20 \\
35 \\
15 \\
17 \\
37 \\
36 \\
34 \\
24\end{array}$ & $\begin{array}{l}- \\
+ \\
- \\
+ \\
+ \\
+ \\
+ \\
+ \\
+ \\
+\end{array}$ & $\begin{array}{l}2.7 \\
1.5 \\
3.7 \\
2.7 \\
1.9 \\
2.6 \\
3.2 \\
2.4 \\
3.2 \\
3.6\end{array}$ & $\begin{array}{l}1.7 \\
0.9 \\
1.0 \\
1.9 \\
1.9 \\
1.7 \\
2.0 \\
1.0 \\
2.3 \\
2.3\end{array}$ & $\begin{array}{l}43 \\
33 \\
60 \\
45 \\
41 \\
47 \\
55 \\
44 \\
58 \\
54\end{array}$ & $\begin{array}{l}2.5 \\
1.8 \\
3.6 \\
2.8 \\
2.4 \\
2.4 \\
3.7 \\
2.6 \\
2.9 \\
3.0\end{array}$ & $\begin{array}{l}1 \cdot 6 \\
1 \cdot 1 \\
2 \cdot 2 \\
2 \cdot 1 \\
2 \cdot 4 \\
1 \cdot 4 \\
2 \cdot 4 \\
1 \cdot 1 \\
2 \cdot 2 \\
1 \cdot 5\end{array}$ & $\begin{array}{l}41 \\
32 \\
58 \\
53 \\
45 \\
47 \\
54 \\
43 \\
56 \\
49\end{array}$ & $\begin{array}{l}2 \cdot 6^{*} \\
1 \cdot 6^{*} \\
2 \cdot 8 \\
2 \cdot 4^{*} \\
2 \cdot 1 \\
2 \cdot 8 \\
2 \cdot 7 \\
2 \cdot 9^{*} \\
3 \cdot 6^{*}\end{array}$ & $\begin{array}{l}1.3 \\
1 \cdot 1 \\
1.9 \\
1.3 \\
1.5 \\
2.0 \\
1.7 \\
1.9 \\
2.2\end{array}$ & $\begin{array}{l}45 \\
30 \\
51 \\
41 \\
43 \\
54 \\
42 \\
56 \\
54\end{array}$ & $\begin{array}{l}2 \cdot 6 \\
1 \cdot 7 \\
3 \cdot 6^{*} \\
2 \cdot 7^{*} \\
2 \cdot 6 \\
2 \cdot 4^{*} \\
2 \cdot 9^{*} \\
2 \cdot 3^{*} \\
3 \cdot 0 \\
3 \cdot 6\end{array}$ & $\begin{array}{l}1.8 \\
0.8 \\
1.4 \\
1.5 \\
1.6 \\
1.4 \\
1.6 \\
1.2 \\
1.5 \\
2.1\end{array}$ & $\begin{array}{l}40 \\
31 \\
53 \\
57 \\
40 \\
48 \\
58 \\
46 \\
64 \\
58\end{array}$ \\
\hline \multicolumn{3}{|c|}{$\begin{array}{l}\text { Mean } \\
\text { Standard deviation }\end{array}$} & $\begin{array}{l}2 \cdot 7 \\
0 \cdot 7\end{array}$ & $\begin{array}{l}1 \cdot 7 \\
0 \cdot 5\end{array}$ & $\begin{array}{r}48 \\
8\end{array}$ & $\begin{array}{l}2 \cdot 8 \\
0 \cdot 6\end{array}$ & $\begin{array}{l}1 \cdot 8 \\
0 \cdot 5\end{array}$ & $\begin{array}{r}48 \\
8\end{array}$ & $\begin{array}{l}2 \cdot 6 \\
0.6\end{array}$ & $\begin{array}{l}1.6 \\
0.4\end{array}$ & $\begin{array}{r}46 \\
8\end{array}$ & $\begin{array}{l}2 \cdot 7 \\
0 \cdot 6\end{array}$ & $\begin{array}{l}1 \cdot 5 \\
0 \cdot 3\end{array}$ & $\begin{array}{l}49 \\
10\end{array}$ \\
\hline
\end{tabular}

$\mathrm{FEV}_{1}=$ litres BTPS

$V_{E}=$ mean minute ventilation

$*$ = test performed first on day 2 
$\mathrm{FEV}_{1}$ values or logarithms of values were used. Response to exercise was insignificantly different from that to hyperventilation on the same day, or the matched test on day 1 .

Temperature in the laboratory on test days varied from $19^{\circ} \mathrm{C}$ to $23.5^{\circ} \mathrm{C}$ but for any patient, variation was never greater than $0.5^{\circ} \mathrm{C}$ within a day, or $1.5^{\circ} \mathrm{C}$ between days. The cylinder air used has for practical purposes zero humidity.

\section{Discussion}

With the recent suggestion that respiratory heat exchange is the triggering stimulus for exerciseinduced bronchoconstriction, ${ }^{5}$ any provocation test must take into account temperature and humidity of inspired gas and minute ventilation.

Since our laboratory temperatures were fairly constant, no attempt was made to alter inspired air temperature. The use of cylinder gases ensured that the humidity of inspired air was constant and near zero. The small amount of rebreathing permitted by the Otis-McKerrow valve (dead space $115 \mathrm{ml}$ ) was assumed to have a constant effect on humidity for each patient. The continuous monitoring of inspired and expired gas flow during hyperventilation allowed relevant instructions to be given to the patients regarding respiratory rate and depth to maintain their minute ventilation at target level. During treadmill exercise, ventilation control was found to be more difficult. It was impossible to predict the effect of alteration of treadmill speed on minute ventilation in these untrained subjects.

No previous training was necessary for patients to carry out hyperventilation satisfactorily. All patients preferred hyperventilation to exercise as the former required less physical exertion and was not associated with dyspnoea on completion of the six-minute period.

The magnitude of change in $\mathrm{FEV}_{1}$ shown by the patients was greater than expected when compared at similar temperature, humidity, and ventilation rate with the data of Deal et al. ${ }^{7}$ However, our method required each subject to achieve maximum sustained voluntary ventilation rate. This not only provided a stronger provocation to the airways but also made provocation equivalent in each patient. In the later study by Deal et $a l^{8}$ where hyperventilation with cold air was used and patients breathed at two-thirds indirect maximum breathing capacity, response was very similar to that found in the present study.

Hyperventilation challenge was similar to exercise in its effect on airways. This has been shown by other authors. ${ }^{67}$ Anderson et al calculated the coefficient of variation for pairs of treadmill exercise tests carried out two hours apart, and found it to be $\frac{\overrightarrow{5}}{\frac{7}{0}}$ $25 \%$. The coefficient of variation for our nine $\frac{O}{\partial}$ patients who responded to hyperventilation tests $\frac{\overline{\bar{N}}}{\overline{0}}$ on all three occasions was $18 \%$ (patient $5 \operatorname{could}$ not $\overrightarrow{\mathbb{D}}$ be included in analysis since failure to respond on two out of three tests invalidates calculation of क standard deviation). This is in agreement with the $\overrightarrow{0}$ results of Anderson and the variation in bronchial lability of $20 \%$ found by Jones. ${ }^{11}$ Our patient $5 \vec{\omega}$ did not show an asthmatic response on day 1 but had a "normal" asthmatic response on day 2 after both hyperventilation and exercise. This suggests $\omega$ that the lack of response on day 1 was not caused by 00 inadequacy of the hyperventilation challenge, but may have been a reflection of altered reactivity of the patient's airways which cannot be explained in terms of differing pre-test FEV $_{1}$ values. This variability must be borne in mind both in screening for exercise-induced asthma and in clinical research.

Our findings suggest that isocapnic hyperventila- tion with dry air is a reliable method of inducing $0_{\infty}^{\circ}$ bronchoconstriction, and has practical advantages over exercise testing in untrained subjects. It can also be performed with less complicated equipment than that required for isocapnic hyperventilation with cold air.

\section{References}

1 Floyer J. A Treatise of the asthma. London: Wilkin ante Innys, 1698.

2 Anderson SD, Connolly NM, Godfrey S. Comparison of bronchoconstriction induced by cycling and running Thorax $1971 ; 26: 396-401$.

3 Miller GJ, Davies BH, Cole TJ, Seaton A. Comparison of the bronchial response to running and cycling in asthma using an improved definition of the response to work Thorax 1975;30:306-11.

4 Chen WY, Horton DJ. Heat and water loss from the airways and exercise-induced asthma. Respiration 1977 을 34:305-13.

5 McFadden ER, Ingram RH. Exercise-induced asthma observations on the initiating stimulus. $N$ Engl $J$ Me@. $1979 ; 301$ :763-9.

6 Zeballos RJ, Shturman-Ellstein R, McNally JF, Hirsch JES Souhrada JF. Role of hyperventilation in exercisen induced bronchoconstriction. Am Rev Respir Dis 1978 118:877-84.

7 Deal EC, McFadden ER, Ingram RH, Jaeger JJ. Hypere pnoea and heat flux: initial reaction in exercise-induced asthma. J Appl Physiol 1979;46:476-83.

8 Deal EC, McFadden ER, Ingram J, Breslin FJ, Jaeger JJ Airway responsiveness to cold air and hyperpnoea in ${ }^{+}$ normal subjects and in those with hay fever and asthma.o Am Rev Respir Dis 1980;121:621-8.

9 Clark TJH, Freedman S, Campbell EJM, Winn RR. Th. ventilatory capacity of patients with chronic airway obstruction. Clin Sci 1969;36:307-16.

10 Anderson SD, Silverman M, König P, Godfrey S. Exerciseg induced asthma. BrJ Dis Chest 1975;69:1-39.

11 Jones RS. Assessment of respiratory function in the asthmatic child. Br Med $J$ 1966;2:972-5. 